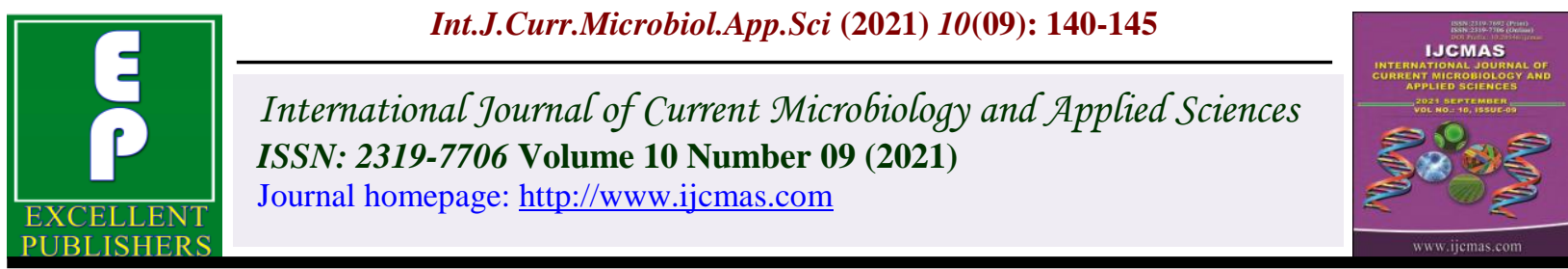

Review Article

https://doi.org/10.20546/ijcmas.2021.1009.016

\title{
Immunomodulation of Domestic Animals Using Conventional Methods and Panchgavya
}

\author{
Rinkal Sundriyal $^{1 *}$, Aarti Adhikari ${ }^{1}$ and Siddharth Chaudhary ${ }^{2}$ \\ ${ }^{1}$ Department of Veterinary Pharmacology and Toxicology, CVASc., GBPUAT, \\ Pantnagar, Uttarakhand, India \\ ${ }^{2}$ Department of Veterinary Medicine, IVRI, Izatnagar, Bareilly, Uttar Pradesh, India \\ *Corresponding author
}

Keywords

Immunomodulators, Ayurveda,

Medicinal plants, Algae, Panchgavya (Cowpathy)

Article Info

Accepted:

10 August 2021

Available Online:

10 September 2021
A B S T R A C T

With increase in the prevalence of diseases mainly the new emerging diseases, finding a cure is like dodging a bullet. Not only this, but the new world also has to fight against emerging drug resistance among pathogens. Overall, the possibility of survival not only depends on combating the diseases by using expensive resources but it now relies more on immunity building. This fact is applicable in the livestock sector as well. The farmer's economy mainly depends upon the production performance of his livestocks. Also, maximum part of his earnings spends on the feed, fodder, feed additives and other production enhancing drugs. But a single sick animal can disturb the entire planning of a small farmer. Hence the main objective of this article is to focus on the herbal ways that could help in the immunomodulation of livestock and thus conserving both time and money of the farmers. Many villagers of India use their heritage and knowledge to defeat the diseases and enhance the productivity of their livestock. On other side, Panchgavya came like a missile against the body ailments of humans. Research product of algae and their use as immunomodulators and production enhancers is now available as a boon in the market. But still there is a lot to search. Overall, relying totally on the drugs for relief, creates loss both in terms of animal health, productivity and farmer's economy. So, prevention via immunomodulators is the best weapon to make our animals healthy and to be wealthy.

\section{Introduction}

Using Tulsi (Ocimum tenuiflorum), Giloi (Tinospora cordifolia), Turmeric (Curcuma longa), Ginger (Zingiber officinale), Neem (Azadirachta indica), Ashwagandha (Withania somnifera), Aloe vera (Aloe barbadensis miller) and many other herbal plants in daily life is inherently transferring from our generations to generations. This is the precious gift of our Ayurveda. The Ayurveda irrespective of focusing on curing the diseases believes in taking certain preventive measures in order to avoid the occurrence of diseases. A famous Sanskrit sloka clearly depicts the principles of Ayurveda along with its main motto. 


\section{Swasthasya Swasthya Rakshanam, Aturasya Vikara Prashamanam Cha}

Ayurveda aims at the protection and maintenance of good health of the healthy people and elimination of or control over the ailments and health-disorders of the unhealthy.

Modulation of immune response is now being recognized as an alternative to conventional chemotherapy against various ailments especially related to the immune system like in the case of organ transplantation or any autoimmune disorder, immunosuppression is needed to avoid complications.

Immunomodulation is made of two-parent words which simply mean modulation of immunity. It includes either immunostimulation (improve the host's defensive mechanism by stimulating the immune response) or immunosuppression (subdue the immune response) by using certain groups of biological and synthetic compounds. In this modern scientific era, the immunomodulatory compounds of plant origin are used to evoke the immune response of an organism non-specifically against pathogens. The immunomodulators are mainly plants derived; hence there are least chances of sideeffects. Also, Ayurvedists are practicing these concepts for centuries. In fact, one of the therapeutic strategies in Ayurvedic medicines is to enhance the overall natural resistance of the body against disease-causing agents instead of neutralizing them directly. This is the basic difference between the therapeutic approach of today's modern science that focuses on chemotherapy and Ayurveda. Overall this approach of Ayurveda is a boon for our industrializing society with many new emerging diseases. We can co-relate this, with the current situation that our country is facing. The havoc caused by the SARS-CoV-II virus is dreadful mainly for those with poor immunity. We don't even have any vaccine yet. So the only measure which could protect us is the use of immuno-boosters.

Our honorable Prime Minister has also said that "Prevention is the only vaccine against COVID". And Ayurveda is the best way to boost up immunity in an easy, affordable and effective manner. This pandemic has told everyone about the importance of Ayurveda.

\section{Role of the Medicinal Plants on Innate and Acquired Immunity}

The medicinal plants have various secondary metabolites that affect our immune system. Natural killer (NK) cells, NK-T cells, T-cells, macrophages, granulocytes (neutrophils, eosinophils basophils) and dendritic cells are the components of innate immunity involved in the immunomodulation. Chlorophytum borivilianum root extract is an effective immunomodulator which not only potentiates non-specific immune response but also improves humoral and cell-mediated immunity. Hence we could use it against infections to enhance our immunological response against foreign particles or antigens. Overall we could use it to boost up the defensive response under normal circumstances. Another example is the ethanolic extract and aqueous extract of Picrorhiza kurroa which acts on the various levels of immune response like release of mediators of hypersensitivity reactions, tissue responses to these mediators in target organs and antibody production ${ }^{[1]}$. The alkaloids, flavonoids, terpenoids, polysaccharides, lactones and glycosides present in the plant extracts are also responsible to cause alterations in the immunomodulatory properties.

Immunomodulation does not affect the microbes directly. Therefore, these agents have an advantage over chemotherapeutic 
agents as there is no chance of emergence of resistance against immunomodulators of natural origin.

\section{Panchgavya Therapy (COWPATHY): A Powerful Tool of Ayurveda}

The Panchgavya principle of Ayurveda constitutes a concoction of cow's urine, milk, curd, ghee and dung as its main ingredients. Hence named Panchgavya.

In research on cow's urine distillate (Kamdhenu ark), scientists found an increase in the phagocytic activity of macrophages and secretion of Interleukin-1 and IL-2. It also acts as a bio enhancer and is known for its synergistic properties with antibiotics. Therefore, it is used as a prophylactic and therapeutic tool for livestock and poultry along with humans.

Cow's ghee has immunomodulatory properties. It improves the cell rejuvenation process and boosts up the healing process of our body. It is a rich source of Butyrate fatty acid which is great for keeping the digestive system healthy and improving immunity.

Consumption of curd/yogurt increases Lactic Acid Bacteria (LAB) in the Gastrointestinal tract (GIT). As a result, it suppresses the growth of pathogenic bacteria and heightens the anti-carcinogenic effect. The LAB influences the Gut Associated Lymphoid Tissue (GALT) and thus increases the production of cytokines and antibodies ( Ig-A, secretary type antibody). Also the mitogenic activity of Peyer's Patches and splenocytes increases.

Cow's milk could be considered as myriads of nutrients along with its antibacterial and antiviral properties. Casein (milk protein) acts as an antiviral and immunoregulatory factor as it regulates the innate immunity both via upregulation to enhance virus killing and down- regulation to reduce detrimental conditions like sepsis. Further, it activates B and T-cell mediated functions. Thus, it links innate immunity with adaptive immunity.

Indian cow's dung possesses superior antimicrobial activity and therefore is used to formulate drugs for several diseases ${ }^{[2]}$.

In 2017, the Science Equity Empowerment and Development (SEED) division of the Department of Science and Development (DST) constituted a National Steering Committee (NSE) for Scientific Validation and Research on Panchgavya (SVAROP).

\section{Immunomodulation in Livestock by Ayurveda}

Traditionally herbal remedies are known to be used all over the country. Herbs like Tulsi, giloi, aloe vera, turmeric etc. are known to possess immunomodulatory properties. Although currently, their use is limited in livestock practice but still is known to be used in many rural settings.

One such example is the use of medicine balls by a few communities in Tamil Nadu. These balls are composed of 3 medicinal plantsVeldt grape or Hadjod (Cissus quadrangularis), Aloe vera and Pergularia or Trellis-vine (Pergularia daemia) and fed to for boosting their immunity ${ }^{[3]}$.

Curcumin, the active principle in Curcuma longa (turmeric) has been found to increase serum level of $\operatorname{IgG}$ and $\operatorname{IgM}$, hence known to have immunomodulatory action in animals ${ }^{[4]}$.

Withania somnifera (Ashwagandha) and Ocimum tenuiflorum (Tulsi) when fed orally to animals alone or in combination are seen to enhance WBCs count and increase peripheral blood monocyte count respectively thereby helping to fight against infections ${ }^{[5],[6]}$. 
Supplementation of Tinospora cordifolia (Giloi) in the diet of peripartum cows is known to increase the total leukocyte count and neutrophils to lymphocyte ratio, preventing postpartum uterine infections ${ }^{[7]}$.

Drenching the juice from Morinda citrifolia (Noni fruit) enhanced the activation of CD4+ and CD8+ T cells in neonatal calves that may have a stimulatory effect in the maturation of their immune system ${ }^{[8]}$.

Aloe vera, as an additive to livestock feed, has great potential for improving nutrient utilization, intestinal health and immune response $^{[9]}$.

Although commercial preparation of the above-mentioned plants is available in the market, the adoption rate of Ayurveda for livestock is still in infancy. However, there is a wide scope for this alternate system of medicine in veterinary practice.

\section{ALGAE: A Magic Bullet for Immunity Modulation of Livestock}

Many marine algae have an abundance of bioactive molecules that provides a wide range of nutritional qualities along with antimicrobial, anticoagulant, anti-proliferative, antitumoral and immunomodulatory effects. The cell wall of Macroalgae or Seaweeds is rich in Sulfated polysaccharides, which is also considered as their characteristic property as it is not found in terrestrial plants or freshwater microalgae or yeast cells. Sulfated polysaccharides play an important role in the regulation of macrophage function, natural killer cells, and T/B lymphocytes, together with the stimulation of the immune responses of lymphocytes and the activation of the complement system ${ }^{[10]}$. In the market, many pharmacological products use these algae as their main component and act as immunomodulators for animals as well as humans.

Some of the examples are as follow:-

\section{ALGIMUN®}

It is a product made by Olmix innovative technology group, France. A research conducted by Olmix group and INRA on Intestinal Porcine Epithelial cells (IPEC-1) using MSP ${ }^{\circledR}$ IMMUNITY made from Ulva armoricana green macroalgae (harvested from the Northern coast of Brittany) showed an increase in the immune-mediators CCL20, IL8 and $\mathrm{TNF}^{[11]}$. As a result, Algimun is the combination of two biologically active macroalgal extracts: MSP IMMUNITY, a green algal extract that reinforces innate and adaptive immune responses; and MSP BARRIER, a red algal extract, which enhances the barrier function of the intestinal mucosa. This product can be used as a feed additive for all animals in order to enhance their disease resistance capability and performance. Algimun can also be used to uplift the immune system of a pregnant sow and increases the lactogenic immunity transfer, overall reducing our dependence on using antibiotics ${ }^{[12]}$.

\section{Aleta $^{\mathrm{TM}}$}

It is a product made from Euglena gracilis which contains a high level of linear Beta Glucan. This product makes a consistent bioavailability of linear Beta-1,3-Glucan which improves gut health, acts as an antiinflammatory agent, improves animal's production performance, levels up its immunity and increases vaccination efficacy ${ }^{[13]}$.

Many microalgae are also known to be used as an active ingredient for making pharmacological immunity boosters ${ }^{[14],[15]}$. These products not only enhance the immunity 
but also resist the use of antimicrobial drugs by uplifting the body's disease resistance. Thus they also help us to combat the antibiotic drug resistance shown by pathogenic microbes.

\section{Future Perspectives}

This is the age of Science and Technology where revolutionized technology has become an essential part of our daily lifestyle. No doubt, today every disease has its remedy. But in many cases, the cure is worse than the disease. As there are still many diseases with no cure, so prevention becomes the best remedy. Overall, if our experienced researchers work along with the knowledge of modern technologies then they could give an advanced and quality research in the veterinary field with foresight of not attaining pain to sustain the life. Remember, it's easier to stop something happening at its first stage than to repair the damage after it has happened.

\section{References}

1. Preeti Sharma et al., National Journal of Physiology, Pharmacy and Pharmacology. https://www.njppp.com/fulltext/281487571016.pdf (accessed 2017, March 18)

2. Panchgavya: Immune-enhancing and Therapeutic. An overview of panchgavya therapy regarding immune-enhancing and therapeutic perspectives in safeguarding animal and human health Advertisement Content uploaded by Kuldeep Dhama.

3. Gilon, Catherine., "Cattle Farmers Revive Traditional Herbal Remedies - Village Square".

Villagesquare,https://www.villagesquare.i n/2019/09/09/cattle-farmers-revivetraditional-herbal-remedies/ (accessed 2019, September 09)
4. Catanzaro, M., Corsini, E., Rosini, M., Racchi, M., \& Lanni, C. (2018). Immunomodulators Inspired by Nature: A Review on Curcumin and Echinacea. Molecules (Basel, Switzerland), 23(11), 2778.

https://doi.org/10.3390/molecules2311277 8

5. Davis L, Kuttan G. Immunomodulatory activity of Withania somnifera. $\mathrm{J}$ Ethnopharmacol. 2000 Jul;71(1-2):193200. doi: 10.1016/s0378-8741(99)00206-8. PMID: 10904163.

6. Mohamed, Shynu \& Gupta, Praveen \& Sharma, Bhaskar \& Saini, Mohini. (2007). Immunomodulatory potential of Ocimumtenuiflorum extracts in bovine peripheral blood mononuclear cells in vitro. 9. 31-36.

7. BS;, M.S.P., Effects of supplementation of Tinospora cordifolia to crossbred cows peripartum. Animal reproduction science. https://pubmed.ncbi.nlm.nih.gov/21163594 /(accessed 2020, November 13).

8. Effect of Morindacitrifolia in growth production and immunomodulatory properties in livestock and poultry a review.

https://www.researchgate.net/publication/3 03527834

9. Prashant yogi., Use of Aloe Vera as potential herbal feed additives in dairy cattle., https://www.pashudhanpraharee.com/useof-aloe-vera-as-potential-herbal-feedadditives-in-dairy-cattle/(accessed 2020, May 20)

10. Michael ash., Sulfated Polysaccharides: Immune Boosters Extracted from Sea Lifehttps://www.clinicaleducation.org/resource s/reviews/sulfated-polysaccharidesimmune-boosters-extracted-from-sealife/(accessed 2018, March 14)

11. Immunomodulating effect of a seaweed extract from Ulva armoricana in the pig: Specific $\operatorname{IgG}$ and total $\operatorname{IgA}$ in colostrum, 
milk, and blood_Bussy et al., https://www.sciencedirect.com/science/arti cle/pii/S2451943X18302308

12. ALGIMUN®_https://www.olmix.com/ani mal-care/algimun (accessed 2020, March 16)

13. ALETA $^{\text {TM: }}$ Product for Animal Immune Response: Kemin India. https://www.kemin.com/in/en/products/ale ta (accessed 2020, February 21)
14. Microalgae with Immunomodulatory Activities. Riccio \& Lauritano. https://pubmed.ncbi.nlm.nih.gov/31861368

15. Ahmad et al., Oceans as a Source of Immunotherapy. https://www.mdpi.com/460242(accessed 2020, March 09)

\section{How to cite this article:}

Rinkal Sundriyal, Aarti Adhikari and Siddharth Chaudhary. 2021. Immunomodulation of Domestic Animals Using Conventional Methods and Panchgavya. Int.J.Curr.Microbiol.App.Sci. 10(09): 140-145. doi: https://doi.org/10.20546/ijcmas.2021.1009.016 